\title{
EDUCATIONAL APPLICATION USED TO SIMULATE THE FUNCTIONALITY OF A GASOLINE INJECTION SYSTEM

\author{
${ }^{1}$ S. Rațiu, ${ }^{2}$ V. Alexa, ${ }^{3}$ I. Kiss
} \\ ${ }^{1}$ Univ. Politehnica Timişoara, Faculty of Engineering Hunedoara, Revoluției street, no. 5, 331128, Hunedoara, Romania e-mail: sorin.ratiu@fih.upt.ro
}

\begin{abstract}
This paper presents an educational application, with practical realization, regarding the functionality simulation of a gasoline injection system using a computer and a peripheral afferent, along with its control circuit. The application replaces the ECU (Engine Control Unit) and controls a demo injection rail, equipped with four gasoline injectors with different shapes of flow. The equipment provides the flow shape visualisation and injection parameters change according to the engine load conditions, which can be simulated by the electronic equipment through the virtual interface. The system allows the determination of the gasoline amount injected by the various types of fuel injectors, in a certain period of time and at different pressures of the fuel, depending on the load and the speed of the engine.
\end{abstract}

Keywords: gasoline injection, simulation, injection parameters

\section{INTRODUCTION}

The fuel injection in modern internal combustion engines is currently carried out exclusively under electronic control. In most cases, the control unit is represented by the "injection computer". This unit acts on the execution elements (injectors, spark plugs, motors, valves, regulators etc.) using signals which are influenced by the reaction parameters coming from the position sensors, speed, pressure, temperature, etc. The complexity of the processes taking place in a system of fuel injection management for an internal combustion engine requires extra effort for a proper understanding of the operating principles. This is the reason for realising this paper, which is intended to be an intuitive practical application able to simulate the complex electronic control of injection, through a PC and specialized software. The application provides an intuitive and friendly analysis of the processes occurring during the operation of an injection computer.

The assembly is designed so as, via a PC running an application in the dedicated programming environment, to control an induction fuel injector rail through an electronic circuit with transistors, which communicates with the PC using the NI6221data acquisition board from the company National Instruments. In other words, instead of the engine control unit, it was used a PC running the virtual application and the NI6221data acquisition board, as peripheral for communication with the external components.

The difference relative to the input and output connections to the control unit is the fact that the acquisition of signals coming from the sensors is realised directly with the NI6221, without any intermediate circuit, and the injector operation benefits from 4 intermediate control circuits provided with bipolar transistors. Everything related to the acquisition of signals from the sensors and generation of signals from the processing unit becomes the task of the two elements.

The assembly described above - consisting of two distinct parts: the software (represented by the virtual application, which controls the injector opening) and the hardware (represented by the fuel circuit and injector rail) - is intended as an experimental stand with exclusive didactical applicability. The aim is to observe the main characteristics of a fuel feeding and injection system, as follows:

- identification of components for the control system, data acquisition and generation system, and fuel injection system;

- $\quad$ analysis of the different types of signals that can be used to actuate the injectors;

- establishing the principles of injector operation in accordance with the control electronics;

- visualization of the injection cadence and amount injected, depending on the engine speed and load;

- programming of injection computers. 


\section{APPLICATION HARDWARE DESCRIPTION}

The hardware assembly is made of various devices and modules, i.e. the PC, the NI6221 communication peripheral, the control circuit with bipolar transistors (BD237 and $\mathrm{BC} 107$, respectively), the rail with 4 different types of injectors, the fuel pump, the litrometric probe, accelerator pedal and power supply.

Taking into account the component elements and their functional role, it was realised the diagram of the fuel injection system, shown in Fig. 1.

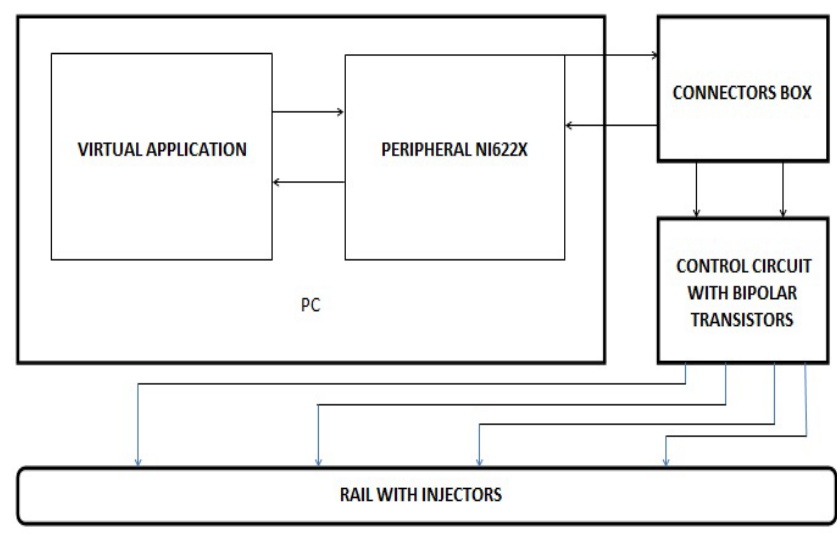

Figure 1. Functional diagram of the application

For easier identification of the experimental stand components, it was chosen a solution that enabled us to easily observe and even disconnect all the components. Based on the geometrical shape of a fuel rail fitted on the Opel Astra G engine, made in 2007, it was designed a container in which the injectors supply gasoline, container that enables us to watch the quality of the pulverized fuel flow shape.

Moreover, the device contains four tubes for the quantitative determination of fuel consumption, at different regimes of engine operation and various rail pressures.

To see the shape of the injector nozzle heads, it was designed a system that enables the common rail to rotate around its horizontal axis.

In order to obtain variable pressures on the supply line and on the common rail, the fuel pump was connected to a circuit which, by reducing or amplifying voltage, decreases or increases the pressure.

In order to get the exact moments for triggering the fuel injection and, especially, the time interval within which the injectors spray the fuel, they are connected to a circuit simulating the injection computer.

The source of DC voltage, ensuring the supply of necessary energy for the electronic control circuit, litrometric probe and fuel pump, is provided with three pairs of terminals which are able to provide adjustable pressure to two of them, and a DC voltage of $5 \mathrm{~V}$ to the other one.

Besides the software, the PC assembly includes also a physical part, represented by the data acquisition board. It communicates with the other components through the connector block, where the control terminals for each injection circuit are connected.

The electronic control circuit is the element that transposes the signals generated by the data acquisition board and modelled by the virtual application in useful signal, able to command the injectors to carry out the fuel spray.

The injectors are placed on the common rail, where the fuel is brought from the tank, previously passed through a pressure regulator which is intended to maintain the rail pressure within a certain range.

The fuel tank houses the electric fuel pump, the level sensor with mobile buoyant, element that converts the level into a set of electrical parameters in the form of an adjustable resistor with cursor. 
The command originating from the accelerator pedal was realised through a USB port, providing a signal to a wide range of values, in progression, that increase according to the pedal pushing force. The entire assembly is interconnected. Fig. 2 presents an overview of the application hardware.

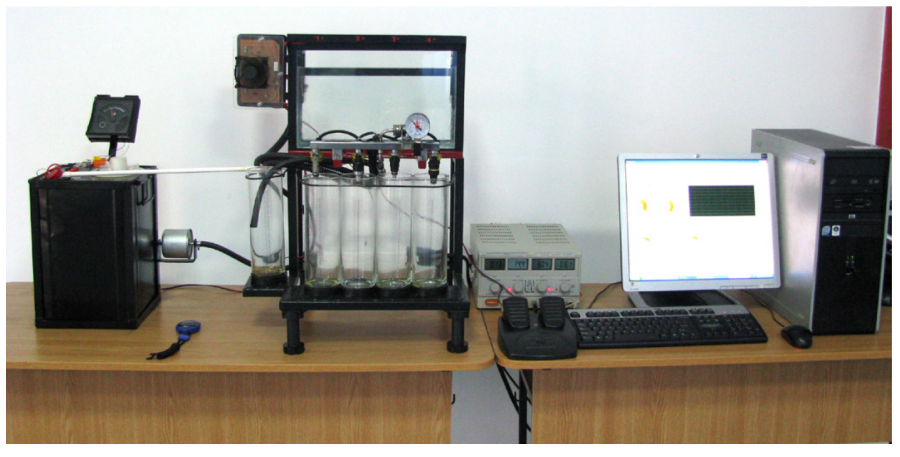

Figure 2. Overview of the application hardware

\section{DESCRIPTION OF THE VIRTUAL APPLICATION}

\subsection{The front panel}

The front panel is the direct user interface for the virtual instrument in which operates, being provided with a toolbar and a range of control elements (Fig. 3).

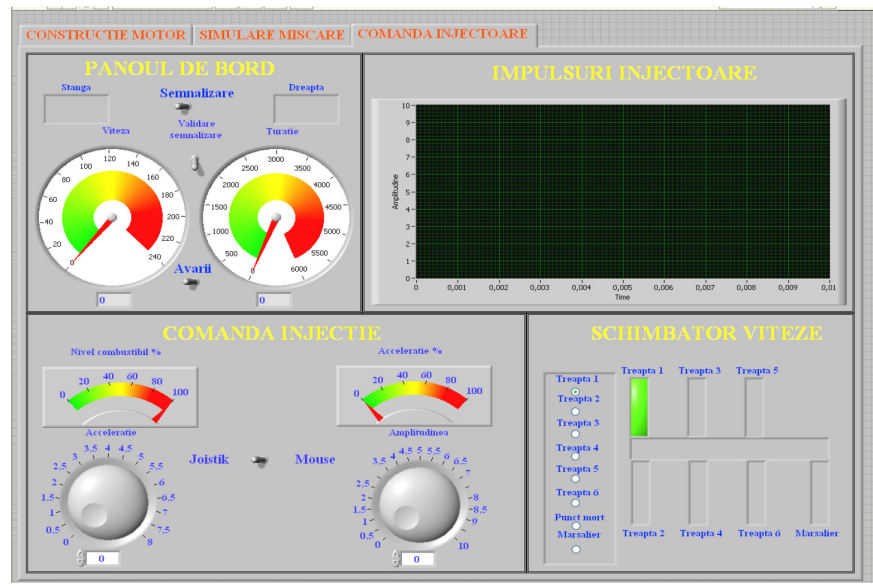

Figure 3. Overview of the front panel

The user can change the input value for certain parameters, or view the value generated by a virtual instrument, each control or indicator having a predefined datum type, to which it is associated, the most common being the numeric ones, of Boolean or string type. To display the processed data, it can be also used indicators of oscilloscope type, in which the different waveforms of the signals can be seen, whether they are digital or analogue.

As shown in Fig. 3, the front panel is divided into four sections, entitled "Dashboard", "Injection control", "Injector pulse" and "Gear shift". In the subsection "Dashboard", can be seen either the engine speed or the vehicle speed. The "Injection control" panel allows changing the engine speed (operation that can also be executed from the accelerator pedal), and its task. The "Injector pulse" panel allows viewing, in real 
time, the form of the injector control signal, and last but not least, the "Gear shift" panel allows simulating the gear changes, in accordance with the engine operating conditions.

\subsection{Signal acquisition from the accelerator pedal}

The accelerator pedal will be the frequency control element for controlling the injectors. In contrast with the other parameters of the signals, the signal provided by the pedal is controlled by a physical element, not a virtual one. The connection of the accelerator pedal to the PC is made via a USB port.

For the present application, it will be used a set of function blocks that will interface the signal given by the accelerator pedal with data types recognized by the utility tool.

\subsection{Simulation of signals}

The electronic control circuit of the injectors requires a continuous, rectangular pulse signal to instantly trigger the injectors of electromagnets, i.e. a voltage drop to close the injectors. This pulse signal has to maintain a certain cadence for each control circuit. The injection parameters will be changed by modifying the signal parameters.

This is implemented in the block diagram of the application. To simulate the signals, it was used the function "Simulate Signal" found in the program library. If the direct control is required, or during the process, the signal simulation parameters can be modified in real time by means of control elements placed on the front panel of the application.

For all the 4 signals that will control one circuit each and, therefore, one injector each, it was chosen control knobs. The need to have an input digital signal will require selecting the value of $5 \mathrm{~V}$ for the peak voltage of the signal.

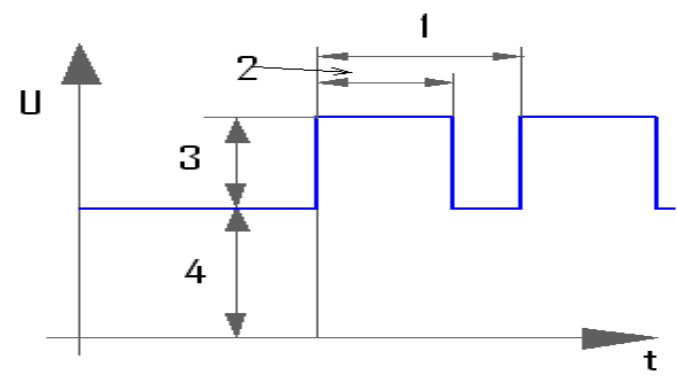

Figure 4. Components of the signal provided by the electronic control circuit

The components of the signal shown in Fig. 4 are: 1 - period, 2 - duty cycle, 3 - amplitude, 4 -offset.

The signal offset represents its position relative to the time axis. In the program, the offset value was selected to permanently be higher than 1 , in order not to have the minimum amplitude of $0 \mathrm{~V}$, for performance reasons.

The duty cycle is the pulse duration, being the parameter that directly affects the length of time when the injectors are open. This allows the fuel consumption control, whereas a higher duty cycle will result in spraying a greater quantity of fuel per cycle. This parameter is adjusted when the engine is subjected to a variable load. The duty cycle can be modified at the input "Duty Cycle" of the signal simulation instrument; it is expressed as a percentage.

The frequency control is achieved by means of the signal from the accelerator pedal, being acquired through the USB port and interfaced through the "Joystick Acquisition" module of the application. This parameter affects directly the engine speed, whereas a greater number of sprays in a given period of time will result in engine speed increase. If somebody wants to change the speed without changing the load, 
then only the frequency of the signal pulses will be increased, and if there is a greater mechanical load, then the duty cycle will be also changed proportionately.

\section{EXPERIMENTAL MEASUREMENTS}

The behaviour of the injection pump to the supply voltage variations can be established by determining the correlation between the voltage variations and the pressure values of the fuel supplied by the pump. As mentioned, changing the supply voltage of the injection pump leads to pressure change in the injector rail. The pressure is visualized by means of the pressure gauge fitted on the rail, and the supply voltage is indicated by the digital voltmeter afferent to the DC voltage source. The graph presented in Fig. 5 shows the variation of the pressure supplied by the pump versus the supply voltage of the pump.

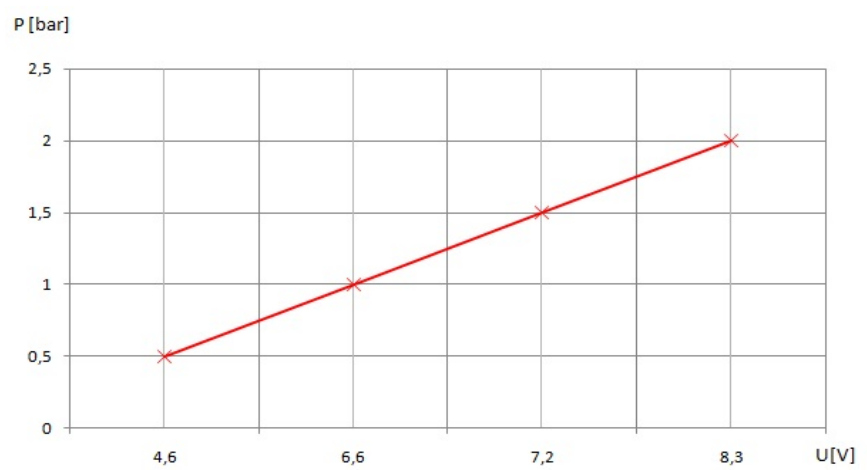

Figure 5. Variation of the fuel pressure versus the supply voltage of the pump

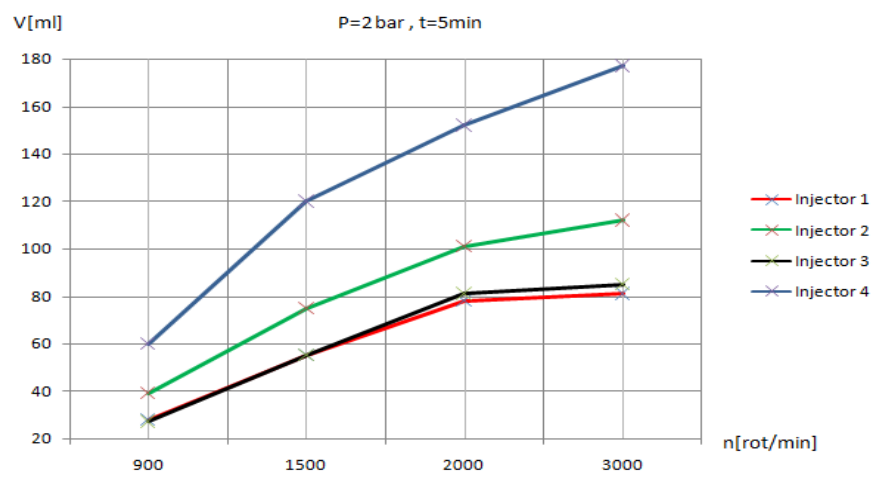

Figure 6. The injected fuel amount versus the injector speed and type

To reflect the structural differences among the various injectors, it was conducted a series of measurements that highlighted the different behaviour of the injectors to identical signals.

For example, it was decided to carry out measurements at a constant 2 bar pressure, at various simulated speeds. The cutting interval was 5 min.

It was measured the amount of fuel injected by each injector, for various speeds, at the same pressure supplied by the pump (Fig. 6). 


\section{CONCLUSIONS}

By making the application presented in this paper, were targeted the following aspects with didactic character:

- familiarization with the phenomena related to fuel injection into internal combustion engines;

- showing how the simulation of continuous pulsed signals realises the injector control;

- being available identical signals to control the various types of fuel injectors, it was revealed the structural differences among them in terms of quality and quantity;

- possibility to observe, in real-time, the form of the injector control signals in the assigned window, placed on the front panel of the application;

- possibility of measuring the flow rate supplied by each injector, by using a set of graduated tubes, in which the injectors are flowing the fuel;

- the observation of the fuel flow quality (geometric shape, number of spray holes, etc.) is facilitated by moving the injector rail in the top of the metal frame, where the glass bowl is placed, which is provided with return to the tank;

- a LED strip facilitates watching the moments when the injectors are flowing the fuel, the injector operation cadence in terms of speed, and the ignition order;

- $\quad$ by using the virtual development utility tool, we demonstrated how to realise complex simulation software without the need for "command line" programming knowledge, but only using diagrams with mathematical function blocks;

- in contrast to the similar stands on the market, it also offers a budget solution, the costs being substantially reduced if choosing this option instead of other brand products.

\section{REFERENCES}

[1] V. Dădârlat and A. Peculea: Analogue and digital circuits, Publisher: U.T. Press, Cluj-Napoca, 2006

[2] D. Ișfãnoi-Trif, C. Gheorghiu, V. Alexa, S. Rațiu: Virtual Application Used to Simulate the Functionality of Engine Control Unit, $3^{\text {rd }}$ International Conference \& Workshop - Mechatronics in practice and education, May 14-15, 2015 - Subotica, Serbia, pp. 66-69

[3] S. Raţiu and L. Mihon: Internal Combustion Engines for Motor Vehicles - Processes and Features, MIRTON Publishing House, Timişoara, 2008

[4] S. Raţiu: Internal Combustion Engines for Motor Vehicles - Processes and Features - Laboratory Experiments, MIRTON Publishing House, Timişoara, 2009

[5] W.W. Pulkrabek, Engineering fundamentals of the internal combustion engine, University of Wisconsin, Prentice Hall, New Jersey, 2003

[6] Ch. F. Taylor: Internal Combustion Engine in Theory and Practice: Vol. 1-2 - 2nd Edition, Revised: Combustion, Fuels, Materials, The MIT Press, 1985

[7] J. Heywood: Internal Combustion Engine Fundamentals, Tata Mcgraw Hill Education, 2011

[8] H. N. Gupta, Fundamentals of internal combustion engines, PHI Learning, 2012

[9] IMechE, Internal Combustion Engines: Improving Performance, Fuel Economy and Emissions, Elsevier, London, 2011

[10] IMechE, Fuel Systems for IC Engines, Elsevier, London, 2012

[11] IMechE, Innovations in Fuel Economy and Sustainable Road Transport, Elsevier, London, 2011

[12] G. Ferrari, Internal Combustion Engines, Società Editrice Esculapio, 2014

[13]P. Van Blarigan, Advanced internal combustion engine research, Sandia National Laboratories, Livermore, 2000

[14] J. Sárosi, J. Gyeviki, A. Véha and P. Toman, Accurate position control of PAM actuator in LabVIEW Environment, Intelligent Systems and Informatics, $301-305,2009$

[15] Automotive handbook, Published by Robert Bosch GmbH, 2007, 7th Edition 